The collection would benefit from colour plates to allow the reader to better engage with the images under discussion in many of the essays. The bibliography is comprehensive and will prove especially useful to those new to the subject. Moving the discussion of breastfeeding beyond the history of maternity, this collection makes an important contribution to the study of gendered relations of care.

ASHLEE BLIGH

York University

\title{
Speroni, Sperone.
}

Canace (1542). Trans. with intro. and notes by Elio Brancaforte.

Carleton Renaissance Plays in Translation 42. Toronto: Centre for Reformation and Renaissance Studies, 2013. Pp. 151. ISBN 978-0-7727-2140-2 (paperback) $\$ 19$.

This first English translation of a Renaissance classic that provoked serious controversy and literary debate is a very welcome addition to the field of early modern studies, and theatre in particular. Brancaforte has edited this volume very thoroughly and thoughtfully. After brief mention of the project's genesis, he presents a comprehensive introduction, divided into seven sections, in order to contextualize Canace from literary and historical perspectives.

The first section, "Sperone Speroni (1500-1588)" (13-18), offers a rather systematic overview of an influential if frequently under-appreciated figure of sixteenth-century letters, whose works and life influenced the dominant debates of the era in Italy and throughout Europe. Brancaforte correctly identifies Speroni as a leading figure in the "questione della lingua" debates, and whose Dialogo delle lingue emphasized "res" over "verba," or, in other words, philosophically rich content over empty form. Criticism of the slavish cultivation of proper Latin style and grammar that overshadows the actual content of the words comes through in all of Speroni's writings, including Canace. Speroni's championing of the vernacular had enormous influence on the work of Joachim du Bellay, for example. In the same manner, the editor makes conscientious mention of the renowned and controversial philosopher Pietro Pomponazzi, who influenced Speroni's works, including his tragedy-such that 
the fundamental issues surrounding philosophy and rhetoric and the true and the true-seeming are emphasized. Speroni's work with the Accademia degli Infiammati is thoughtfully presented as influential to the development of his theories and their practical applications through performance and discussion.

In "Canace and the Senecan Tradition" (18-23), Brancaforte provides a thorough portrait of the influence of Senecan tragedies within the Italian humanist tradition and beyond, especially in relation to the translations of Aristotle's Poetics and Horace's Ars Poetica. Among the many other notable Cinquecento works of tragedy by Giovanni Ruccellai, Ludovico Martelli, Pietro Aretino, and Giangiorgio Trissino, the influence of Giraldi Cinthio's Orbecche of 1541 and the animated debates between him and Speroni concerning the nature of tragedy are well contextualized here. The presence of the Stoic ideal of courage in the face of tyranny, revenge, illicit love (incest between brother and sister), murder, suicide, theodicy, and the Eros-Thanatos relationship in Canace is methodically treated; provocative gestures are then made toward plotting motifs in Elizabethan theatre-in particular, Thomas Kyd's The Spanish Tragedy and William Shakespeare's Hamlet. Here, too, the importance of rhetoric is underlined. When Brancaforte writes of tragedy, "According to the predominant Stoic philosophy, the writing of tragedies was a cognitive endeavor meant to explore human passions as well as the misuse of reason" (23), he is making an important observation equally valid for Speroni's dialogues-which were intended to portray the dialectical process of philosophical reasoning-thus drawing an intriguing parallel between the two genres.

In Canace (24-29), Brancaforte treats the central (and most troubling) theme of incest between Canace and Macareus, since "it relates to the clash between nature and culture, between instinct and the law." Central to this issue and the success of the play is the question of "any form of empathy or tragic passion" (24) for the protagonists since, as brother and sister, they willfully entered into an incestuous relationship that resulted in a child. After briefly alluding to incest within the discussion of anthropological studies and Marxian commodification, the editor succinctly analyzes the practice in "Incest in the Literary Tradition" (29-30) where classical and medieval antecedents are compared and contrasted.

From here, Brancaforte moves to "The Canace Controversy" (31-34) where the evaluations of Cristina Roaf, Giuseppe Toffanin, Girolamo Tiraboschi, Bernard Weinberg, and Marvin Herrick are discussed in terms of 
the issues raised in the tragedy and their performability. Despite the intention to have Angelo Beolco ("Ruzzante") perform the play, Canace was read publicly in 1542 and the contemporary evaluations were based solely on that event since the published text appeared years later-a fact on which Brancaforte is very clear. Thus, we gain another important parallel with Speroni's dialogues, which were praised for their performability after public readings. In particular, the Dialogo d'amore reading led to high praise from Pietro Aretino and, similarly, to much debate years later from the Roman censors for their apparently contentious claims and situations. Giraldi Cinthio's Giudizio d'una tragedia di Canace \& Macareo is carefully discussed concerning four main points: 1 ) the subject matter of incest; 2) catharsis; 3) verisimilitude; 4) versification (32). This section flows elegantly into "Speroni's Response to his Critics" (34-38) where the Paduan's Apologia and Lectures in Defence of Canace are clearly presented and investigated in relation to the Aristotelian precepts of tragedy.

In "Canace and the Treatment of the Incest Theme" (38-46), the editor provides a thorough background to Canace's critical reception. Since most contemporary and current criticism tends to highlight the negative, Brancaforte explores these interpretations carefully, including Felice Paciotto's belief that this tragedy was intended far more as an intellectual exercise for the pleasure of an erudite public than to be represented "in the theatre of the idiots" (39). Just like Speroni's love dialogues-composed as a pleasant break from his philosophical lectures at the University of Padua in the 1520s-the tragedy's innocent intention as an intellectual diversion embroiled its author in heated controversies. With references to the theories of Brecht and Hegel concerning tragedy, and comparative examinations between the earlier Canace by Giovanni Falugi (1531) and John Ford's 'Tis Pity She's a Whore (1633), this final introductory section provides an excellent contextualization of Speroni's tragedy.

As one would presume for a volume that boasts such thorough research, the translation itself is clear and readable, respecting the stylistic issues of the original language as much as possible in the English text. Elio Brancaforte has produced a well-annotated and thought-provoking edition of an important sixteenth-century tragedy that richly deserves further critical attention.

ROBERT BURANELLO

University of Ottawa 